\title{
Cross-frontal variation in growth rate and prey availability of larval North Sea cod Gadus morhua
}

\author{
Peter Munk* \\ Department of Marine Ecology and Aquaculture, Danish Institute for Fisheries Research, Charlottenlund Castle, \\ 2920 Charlottenlund, Denmark
}

\begin{abstract}
Fish larvae are often concentrated in areas of hydrographic fronts and frontal processes are likely to affect larval growth and survival. The potential influence could be direct through impact from specific physical parameters, or it could be indirect through enhancement of prey availability in the frontal zone. The present paper examines the physical-biological linkages for cod larvae distributed across hydrographic fronts in the NE North Sea, hypothesising that larval growth rate and prey availability are promoted in the central frontal zone. Cod larvae and zooplankton were sampled along a series of cross-frontal transects in May of 1992, 1993 and 1994. Growth rate was ascertained from age-at-length, using otolith examination, while prey availability was estimated from copepod abundance and prey preference curves. Larval growth rate was significantly promoted at the front, and significant along-frontal and interannual differences were also found. Prey availability was enhanced in the frontal areas, but there was no significant relationship between availability and corresponding estimates of larval growth rate. The findings stress the need to consider environmental variability when ascertaining growth rates of larval fishes and point to the influence of hydrographic fronts in the survival and recruitment processes of fishes.
\end{abstract}

KEY WORDS: North Sea · Hydrographic fronts · Cod larvae · Prey availability · Otolith microstructure $\cdot$ Specific growth rate $\cdot$ Differential mortality $\cdot$ Recruitment

\section{INTRODUCTION}

Recruitment in marine fish stocks depends to a large extent on the life-history of the earliest stages (Houde 1987, Leggett \& Deblois 1994). Mortality is high during these stages, and while larval growth and mortality may be closely linked (Meekan \& Fortier 1996, Nielsen \& Munk 2004), small variations in individual growth rates could result in great variations in abundance of survivors. This relationship was illustrated for a range of species by Houde (1997), who also pointed out that a size-selective mortality could magnify effects of growth-dependent mortality and influence estimates of growth rates. Models on larval growth rate and survival (Rice et al. 1993, Cowan et al. 1996, Pitchford et al. 2005) show that not only the cohort mean growth rate, but also the variance in growth among individuals would influence overall survival. When the variance among individuals is high, survival can be substan- tially higher than would be expected from changes in mean growth rates.

The potential linkages between growth and mortality has led to extensive research on growth variability in fish larvae, research that has been further stimulated by the development of the otolith microstructure technique for growth analysis of the larvae (Campana 2001). Much focus has been directed to the influence of environmental variability, of which temperature and prey availability are believed to have the greatest influence. Studies suggest that surviving larvae grow close to their size- and temperature-dependent capacity (Otterlei et al. 2002, Folkvord 2005); however, the influence of temperature and prey availability are interlinked, and specific temperature optima for growth occur under food limited conditions (Buckley et al. 2004).

Spawning and distribution areas of fish larvae often coincide with areas of hydrographic fronts. These 
areas are characterised by large spatial variability in key physical parameters such as temperature and salinity (Fortier et al. 1992, Lochmann et al. 1997, Lee et al. 2005), and here we often observe enhanced primary production, due to upwelled nutrients, and enhanced concentrations of zooplankton and fish larvae, partly due to converging currents and concentration of non-passive organisms (LeFevre 1986, Franks 1992, Franks \& Chen 1996, Aretxabaleta et al. 2005). Specific physical and biological measures vary markedly within relatively short distances across frontal zones $(<5 \mathrm{~km})$, and both field observations (e.g. Munk 1993) and modelling studies (e.g. Werner et al. 1996, Leising \& Franks 1999) illustrate the potential for large growth variability in these areas.

The present study investigates the cross-frontal growth variability in fish larvae in further detail using larvae collected during an investigation on the early life history of cod and other gadoid fish in the NE North Sea and the Skagerrak (Munk et al. 1995, 1999). In an analysis of larval cod feeding in the area, Munk (1997) showed how the spectra of larval prey biomass varied across the hydrographic front, and illustrated the possible consequences for prey availability to larvae of different size and spatial distribution. Hence, in the present study it is hypothesised that the observed hydrographic variability influences larval growth and survival through direct physical effects on the larvae and/or through hydrographic effects on the abundance and size/species composition of copepod prey.
A specific area crossed by hydrographic fronts is selected for examination of the potential interrelationship between hydrography, zooplankton and larval growth. The basic hypotheses for the study are: (1) physical variability is reflected in biological measures (abundance and growth); and (2) both larval prey availability and larval growth are enhanced in the immediate frontal zone.

\section{MATERIALS AND METHODS}

Cod larvae and mesozooplankton were collected during 3 surveys from 10 to 21 May 1992, 19 to 27 May 1993 and 9 to 18 May 1994. The full sampling programme of these surveys covered the Skagerrak and north-eastern parts of the North Sea, as described in Munk et al. (1999), while the present investigation on cod growth and prey availability focuses on samples from an area between Longitude 5 to $8^{\circ} \mathrm{E}$ and Latitude 56 to $57^{\circ} 40^{\prime} \mathrm{N}$ (Fig. 1). This area is comprised of shallow banks and the shelf slope towards the deep Norwegian Trench, and the stations were aligned along a number of cross-shelf transects, extending from shallow inshore areas towards the shelf break.

Station distances along transects were either 5 or 10 nautical miles (n miles), except for zooplankton in 1992 and 1993 which was sampled at distances of $20 \mathrm{n}$ miles. At each station sampling was initiated by a CTD cast. A Niel Brown CTD was lowered from the surface to $2 \mathrm{~m}$ above the bottom and salinity, temperature and

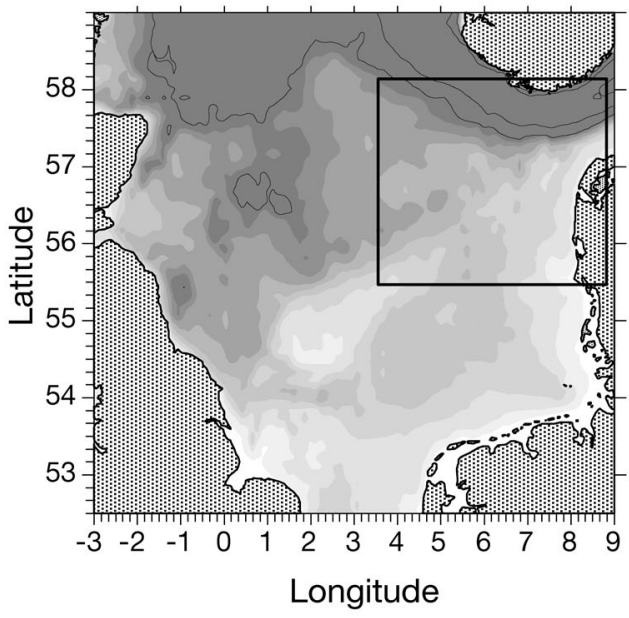

Fig. 1. Left: North Sea; sampling area indicated by rectangle. Right: transects of sampling positions, stations in the front are indicated by a different symbol for each year of sampling; 1992

(•), $1993(\Delta), 1994($ (O). Bathymetry represented by contour lines and different shading

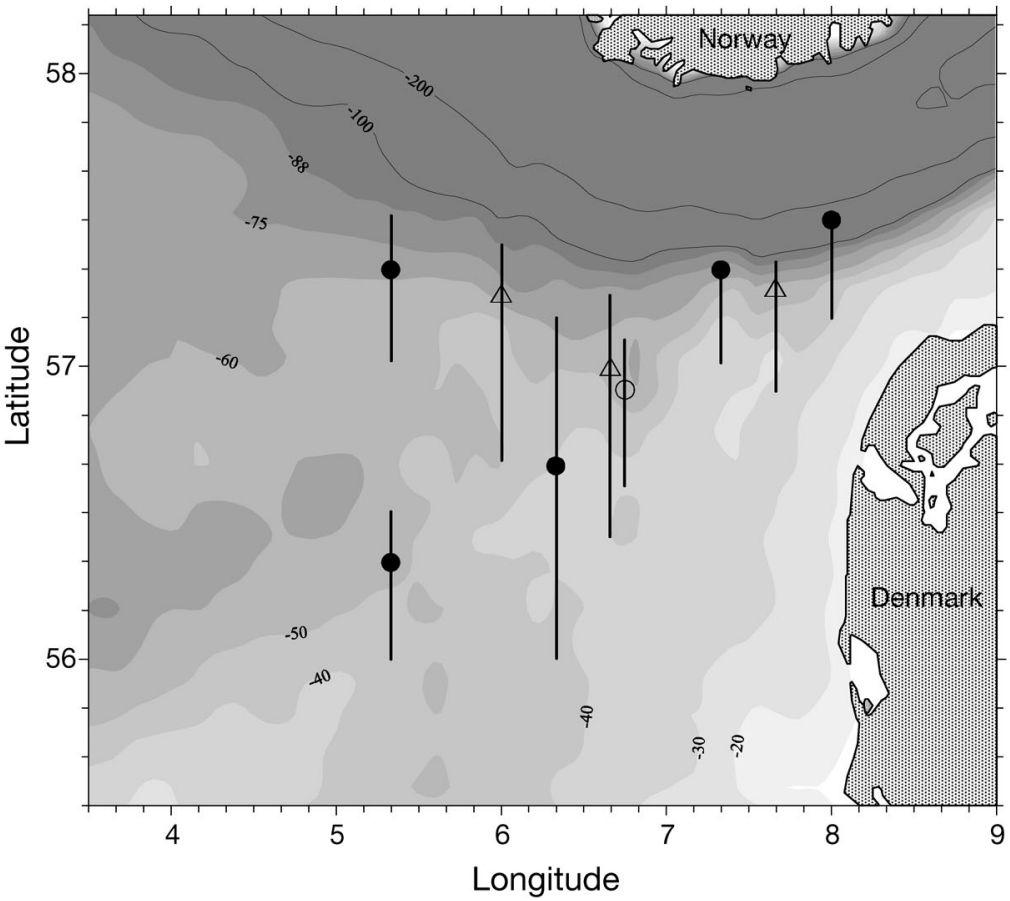


fluorescence were measured at $0.5 \mathrm{~m}$ intervals. The mesozooplankton was then collected using a submersible pump equipped with a $30 \mu \mathrm{m}$ conical net (pump capacity $1.2 \mathrm{~m}^{3} \mathrm{~min}^{-1}$ ). The pump was started at the surface and lowered to $2 \mathrm{~m}$ above sea bottom (max. depth of pump $60 \mathrm{~m}$ ) for a period of approximately $3 \mathrm{~min}$. The zooplankton samples were preserved in $4 \%$ buffered formalin. Finally, fish larvae were sampled using a ring net of $2 \mathrm{~m}$ diameter with a $14 \mathrm{~m}$ long net of $1.5 \mathrm{~mm}$ mesh-size. This net was lowered in an oblique tow to $5 \mathrm{~m}$ above the sea bed at a ship speed of $1.5 \mathrm{~m}$ $\mathrm{s}^{-1}$. On deck all fish larvae were immediately sorted and preserved in $96 \%$ alcohol.

In the laboratory the zooplankton were sorted, and since studies on prey preference of cod larvae in the area suggest that more than $99 \%$ of their prey are copepods (Munk 1997), only copepods were considered in the further analysis of prey availability. The copepods were identified to species and their cephalothorax length measured to within $20 \mu \mathrm{m}$. Random subsampling of the zooplankton sample was continued until at least 150 copepods had been measured. The biomass of the copepods within each length interval was estimated using length-weight keys for each species and nauplius/copepodite stage. The availability of copepod prey to cod larvae was assessed using the prey size spectra of Munk (1997), who proposed that the prey size spectrum of cod larvae could be approximated by a log-normal distribution with a maximum at a prey length:larval length ratio of 0.051 and a width (SD of log-transformed sizes) of 0.23. Besides the influence of prey size on larval preference, a species effect was also apparent (Munk 1997). Hence, the relative preference $(p)$ of given prey species $(s)$ and size interval (i) was estimated by:

$$
p_{s}(i)=e_{s} \times\left(q(i) / \sum_{i=1}^{m} q(i)\right)
$$

where $q(i)=\left\{\exp [\log (i)-\log (\text { preymax })]^{2}\right\} /\left(-2 / \sigma^{2}\right) ; e_{s}$ is the index of relative species preference (Calanus spp.: 1, Pseudocalanus spp.: 1.25, Temora sp.: 0.25 and Acartia spp.: 0.40); prey max $_{\text {is }}$ the prey size interval of maximal preference for a given cod larvae length, estimated from the ratio 0.051 ; and $\sigma$ is the standard deviation of log-transformed prey sizes, set at 0.23 .

Indices of prey availability were then estimated by:

$$
\text { prey }_{\text {available }}=\sum_{i=1}^{m} p_{s}(i) \times a(i)
$$

where $p_{s}(i)$ is the relative preference of the prey species $s$ and $a(i)$ is zooplankton biomass in the ith size interval.

The cod larvae were measured within $0.5 \mathrm{~mm}$ (standard length), and approximately 20 larvae from each sample (station) were used for otolith microstructure examination. Of the 3 pairs of otoliths, the lapilli were chosen for analysis because their ring pattern was more easily interpretable in the later stages. From each cod larvae the 2 lapillus otoliths were transferred to microscope slides, mounted in thermoplastic resin and ground by $1 \mu \mathrm{m}$ lapping film until the central core of the otolith was clearly visible. Otoliths were analysed under a compound microscope with mounted video camera. Images were viewed on a computer screen at magnifications of ca. $3000 \times$ using the $63 \times$ objective of the microscope. The rings were counted manually from the screen, the central prominent dark ring (hatch increment, Geffen 1995) was the first ring counted, and the increments, each composed of the accretion zone and the discontinuous zone, were counted towards the periphery. Each pair of otoliths were analysed twice and the average of the 4 counts was used in the subsequent analysis as the estimated larval age in days (daily increment formation of cod larvae is verified, Geffen 1995). For samples from 1993 and 1994 the radius of each otolith was measured from the centre and along the longest axis; these measurements were not available for the 1992 samples and their radius was thus estimated from the measured area of the otoliths using a conversion factor.

Length-at-age $\left(L_{t}\right)$ was regressed by a non-linear least-square fit to a sigmoidal Laird-Gompertz growth curve:

$$
L_{t}=L_{0} \exp \{\beta[1-\exp (-\alpha t)]\}
$$

where $L_{0}$ is length at hatching, $\alpha$ is the instantaneous growth at the inflection point, and $\beta$ is a dimensionless parameter. Occasionally regressions based on data from single stations led to unrealistic $L_{0}$ estimates; hence for single-station data only $\alpha$ and $\beta$ were fitted and $L_{0}$ was set to the same value, estimated from a regression on all data.

Assuming that larvae caught at a single station all have the same growth history, the Laird-Gompertz curve illustrates the larval growth trajectory, and length increase at age $(t)$ is found from the derivative of Eq. (3):

$$
\mathrm{d} L / \mathrm{d} t=L_{0} \beta \alpha \exp \{\beta[1-\exp (-\alpha t)]-\alpha t\}
$$

Length increase at a given length $\left(L_{\mathrm{m}}\right)$ is then estimated by solving for $t$ at $L_{\mathrm{m}}$ in Eq. (3) and inserting this $t$ in Eq. (4). Subsequently, the weight specific growth rate (SGRW) is estimated from:

$$
\mathrm{SGRW}=3.08 \times(\mathrm{d} L / \mathrm{d} t) / L_{\mathrm{m}}
$$

where 3.08 is the power of the length-weight relationship for 10 to $30 \mathrm{~mm}$ cod (from Munk 1997).

Statistical tests were carried out using the generalised linear model (GLM) in Statistical Analysis System $^{\circledR}$. 


\section{RESULTS}

The specific hydrography of the area has been described in earlier publications (Munk et al. 1995, 1999), and the vertical profiles of density along $6^{\circ} 00^{\prime}$ and $6^{\circ} 40^{\prime} \mathrm{E}$ during the surveys in 1992 to 1994 are illustrated by Munk et al. (1999, their Fig. 2). Frontal characteristics were apparent on the shelf slope and the shallow banks, with a cross-frontal increase in water density in the upper water layers. Following Munk et al. (1999), the location (station) along the cross-shelf transects at which the water density in the upper water column (measured at $20 \mathrm{~m}$ depth) had the highest value, was regarded as the centre of the front (Distance 0). These frontal positions are indicated in Fig. 1. In this paper, the term 'front' is used to designate this specific location, acknowledging that frontal processes take place across a wider zone. Distances in $\mathrm{n}$ miles from the centre of the front (Distance 0) in either an inshore (south, negative values) or an offshore (north, positive values) direction are subsequently used to characterise the other stations along a given transect.

The major fraction of cod larvae was distributed in the depth interval 15 to $40 \mathrm{~m}$ (P. Munk unpubl. data), and this depth interval was used to calculate the temperature experienced by the larvae at the time of sampling. Measurements in this interval were either averaged for single stations or for groups of stations at equal distances from the front (Fig. 2). During the investigation periods of both 1992 and 1993, the $14 \mathrm{~d}$ period preceding sampling had been calm and sunny. Thus, the thermocline had advanced to 20-30 m depth at the time of the survey and relatively warm water masses were included in the $15-40 \mathrm{~m}$ stratum. The temperature stratification was especially pronounced in 1993, and the standard deviations of temperature measurements for this year are outstandingly large (Fig. 2). In 1994 the preceding period had been relatively cold, and consequently the mean temperatures for 1994 are all below those calculated for 1992 and 1993. The cross-frontal variation in temperature of the stratum showed no general trend. In 1993 there was a tendency of declining water temperature in an inshore direction, while an increase in this direction was recorded for the other years. There was no tendency for specific high or low water temperature in the central part of the front.

A great diversity of copepod species was seen across the front (Fig. 3a-c). The following taxa were found: Calanus spp. (C. finmarchicus, C. helgolandicus); Pseudocalanus spp. (P. elongatus, P. minutus, P. acuspes); Temora sp. (T. longicornis); Acartia spp. (A. clausi and others); Oithona spp. (O. atlantica, O. similis, O. plumifera); Centropages spp. (C. hamatus, C. typicus);

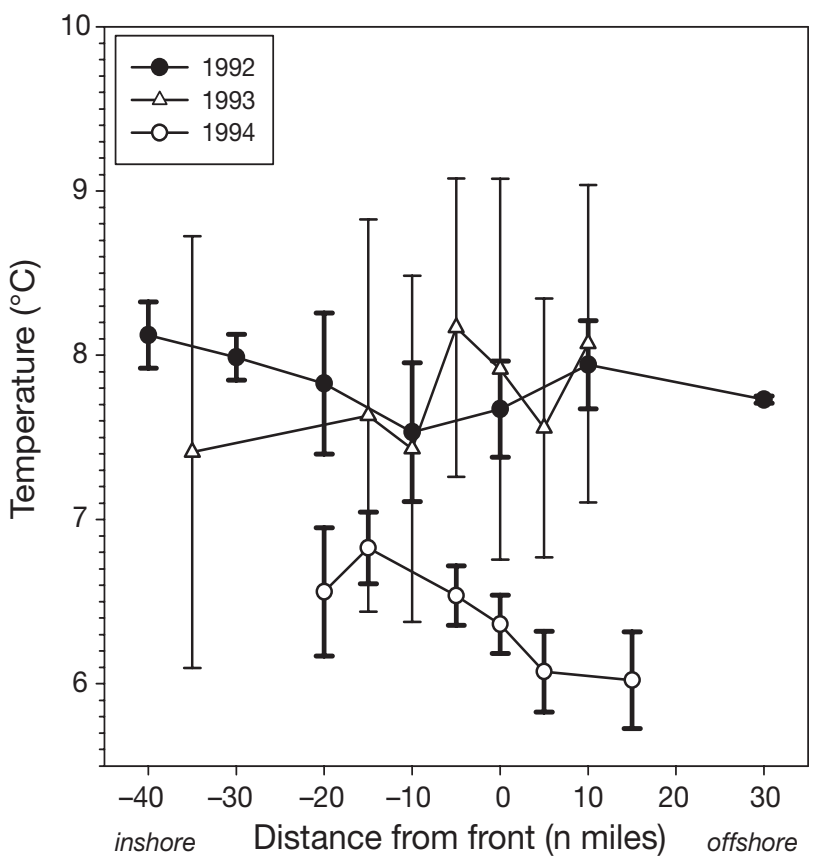

Fig. 2. Average $( \pm \mathrm{SD})$ temperatures of the 15 to $40 \mathrm{~m}$ depth stratum during years of sampling. SDs are for all measures made in stratum at different distances from front (n miles = nautical miles)

Microcalanus sp. (M. pusillus); Paracalanus sp. (P. parvus); Microsetella sp. (M. norwegia); Metridia sp. ( $M$. lucens). Fig. 3a-c shows the abundances of copepods as biomass, which was clearly dominated by Calanus spp., Pseudocalanus spp., Temora sp., Acartia spp. and Oithona spp. Exceptionally high biomasses were found for the large-bodied Calanus spp., which reached densities of $200 \mathrm{mg}$ dry wt $\mathrm{m}^{-3}$ in 1994. During all sampling years the same cross-shelf variation in species composition was observed. Temora sp. and Acartia spp. peaked in abundance inshore of the front, while Calanus spp., Pseudocalanus spp. and Oithona spp. had their highest abundances close to the front. Metridia sp. was predominantly found on the offshore side of the front. Total copepod biomass decreased with increasing distance from the front.

Only fractions of the total copepod biomass were available to the cod larvae in the area. Fig. 3d-f illustrate the relative biomass of prey available to a $15 \mathrm{~mm}$ larva, calculated using Eqs. (1) \& (2) and comprised of the 4 taxa that constitute the majority of available prey to this larval size, Pseudocalanus spp., Calanus spp., Temora sp. and Acartia spp. The $15 \mathrm{~mm}$ larva has been selected because of the prevalence of this size class during the study; prey availability for other abundant size classes showed basically the same spatial variation in abundance and species composition. Most of the large Calanus spp. (i.e. adults and large copepodites) 

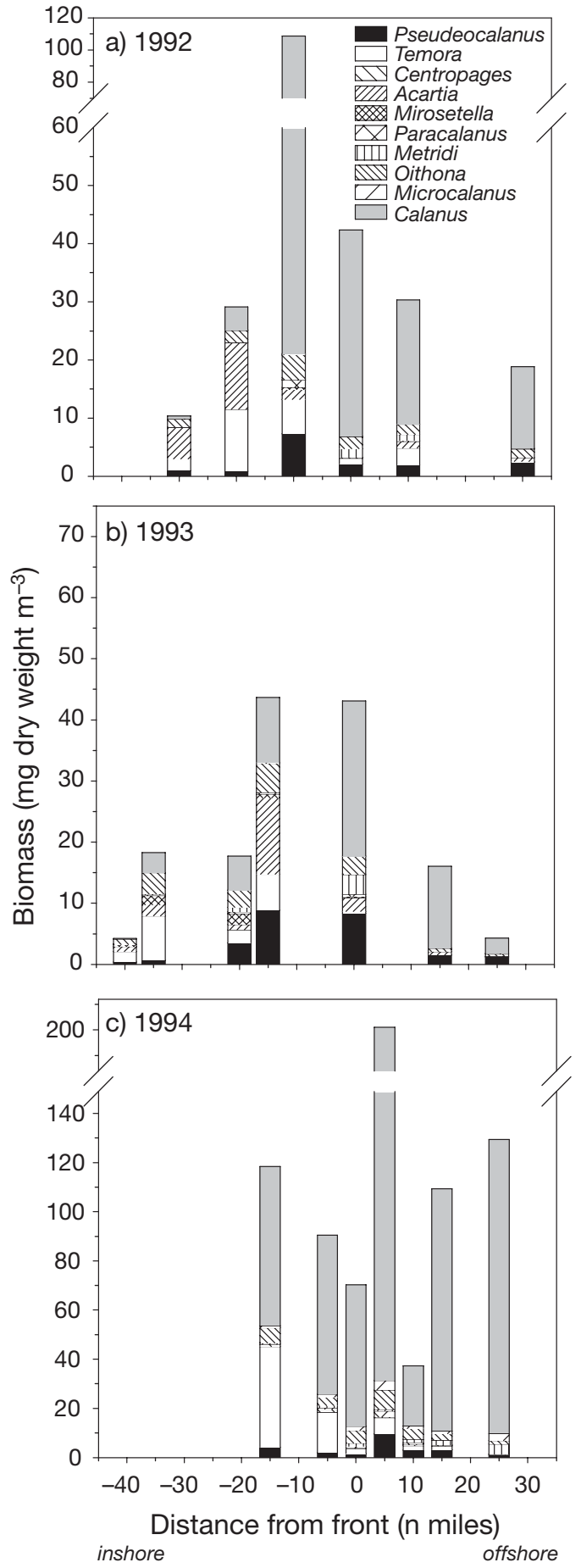
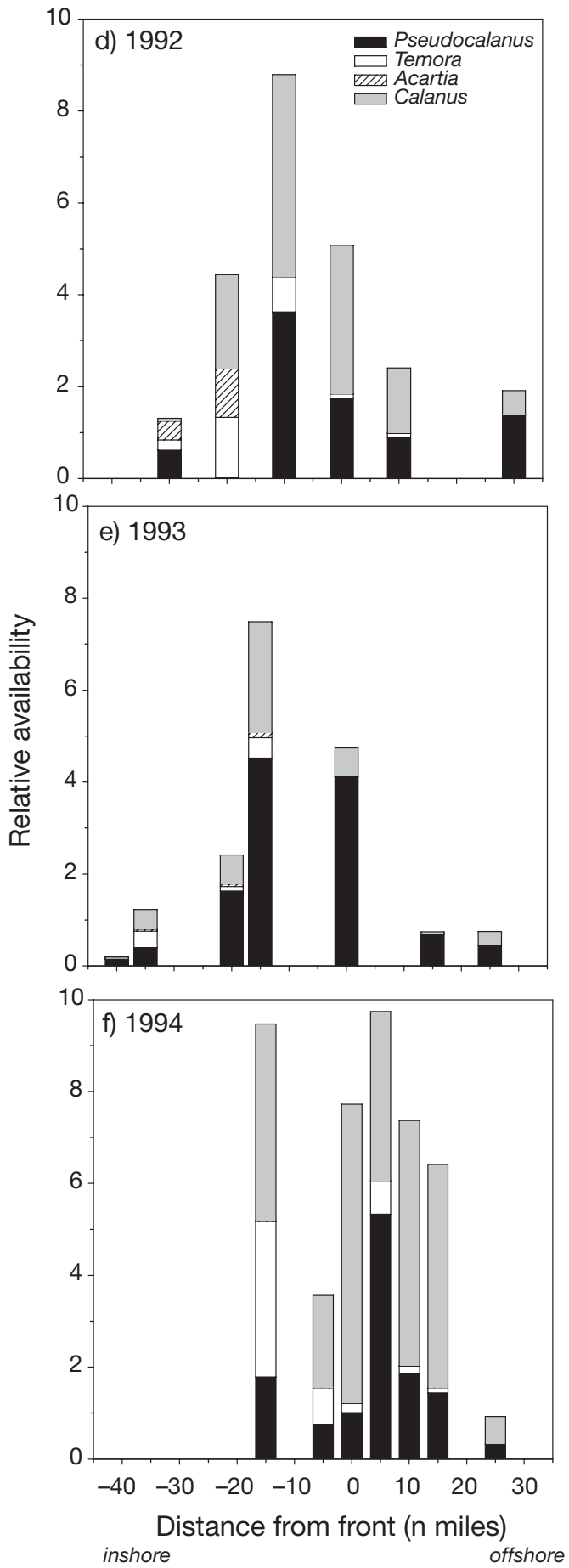

Fig. 3. Biomass and availability of copepods (genus level given) during the 3 years of sampling. (a,b,c) copepod biomass averaged over upper $60 \mathrm{~m}$ of water column for stations at different distances from front; $(\mathrm{d}, \mathrm{e}, \mathrm{f})$ relative availability of 4 important copepod genera as prey for $15 \mathrm{~mm}$ cod larvae, estimated for larvae at different distances from front

was unavailable to the larvae, but other stages comprised an important part of the available prey. Many Pseudocalanus spp. individuals were of appropriate size and contributed significantly to the available prey, while Temora sp. and Acartia spp. were of less impor- tance. Prey availability was higher in the area close to the front, but was not specifically highest at the front stations (Distance 0).

During the full surveys in May 1992 to 1994, cod larval abundance tended to peak at or close to the identi- 
fied front stations (Munk et al. 1999). This was also the case for the restricted part of the surveys that is used in the present investigation, as illustrated by the estimated larval mean abundances at different distances from the front (Distance 0) (Fig. 4). In 1992 and 1994 larval mean length tended to decline in an offshore direction, while no tendency is apparent for larvae sampled in 1993 (Fig. 4).

The relationship between larval size and radius of the otolith was analysed separately for larvae sampled at stations at the front (Distance 0) and at stations outside this area (Fig. 5). Both data sets are well described by linear regression. The slope of the regression for larvae at the front are slightly, but significantly (GLM, $\mathrm{n}=807, \mathrm{p}<0.02$ ) larger than that for the other larvae, i.e. otoliths were relatively smaller at larval length for these larvae. The larval length and age distributions of all specimens examined are illustrated in Fig. 6. Larval length-at-age is fitted for all data by non-linear regression to the Laird-Gompertz growth curve using Eq. (3) (Fig. 6). The estimate of larval size at Age $0\left(L_{0}\right)$ from this regression is $3 \mathrm{~mm}$. Considering the significant shrinkage of larvae during death and alcohol fixation (Radtke 1989), this is in accordance with live length at yolk sac absorption (ca. $4 \mathrm{~mm}$, Geffen 1995). In the subsequent regressions for single stations, $L_{0}$ was set at $3 \mathrm{~mm}$, and only the 2 parameters $\alpha$ and $\beta$ in Eq. (3) were fitted. The size range of larvae available for analysis at given stations varied, and in order to standardise growth estimation, the larval length range for the regression was restricted to $11-26 \mathrm{~mm}$.

Based on the parameter estimation from Eq. (3), specific growth rates in weight (SGRW) for given sizes of larvae were calculated using Eqs. (4) \& (5). Specific growth rates are calculated for 3 larval sizes within the range of larvae analysed, i.e. 12, 15 and $18 \mathrm{~mm}$ (Table 1, Fig. 7). These estimates show declining growth rates with increasing larval size and indicate peaking growth rates at the front (Distance 0). The statistical significance of the apparent decline in growth rates in both an offshore and an inshore direction was analysed by a linear regression model on the effect of year, transect and distance from the front (separate slopes for transects). The decline in growth rate was significant for all larval sizes in the range 12 to $18 \mathrm{~mm}$, in the inshore direction at $\mathrm{p}<0.01(\mathrm{n}=30)$ and in the offshore direction at $\mathrm{p}<0.05(\mathrm{n}=18)$. Differences between transects and between years were significant at $p<0.05$ for the 12 and $15 \mathrm{~mm}$ larvae, but were insignificant for the $18 \mathrm{~mm}$ larvae $(\mathrm{p}>0.05)$. Regressions on the relationships between SGRW for all larval length groups and their respective prey availability estimates were insignificant $(\mathrm{p}>0.05, \mathrm{n}=21)$, and likewise the rela- tionships between SGRW and environmental temperature at time of sampling were insignificant $(\mathrm{p}>$ $0.05, \mathrm{n}=36$ ).
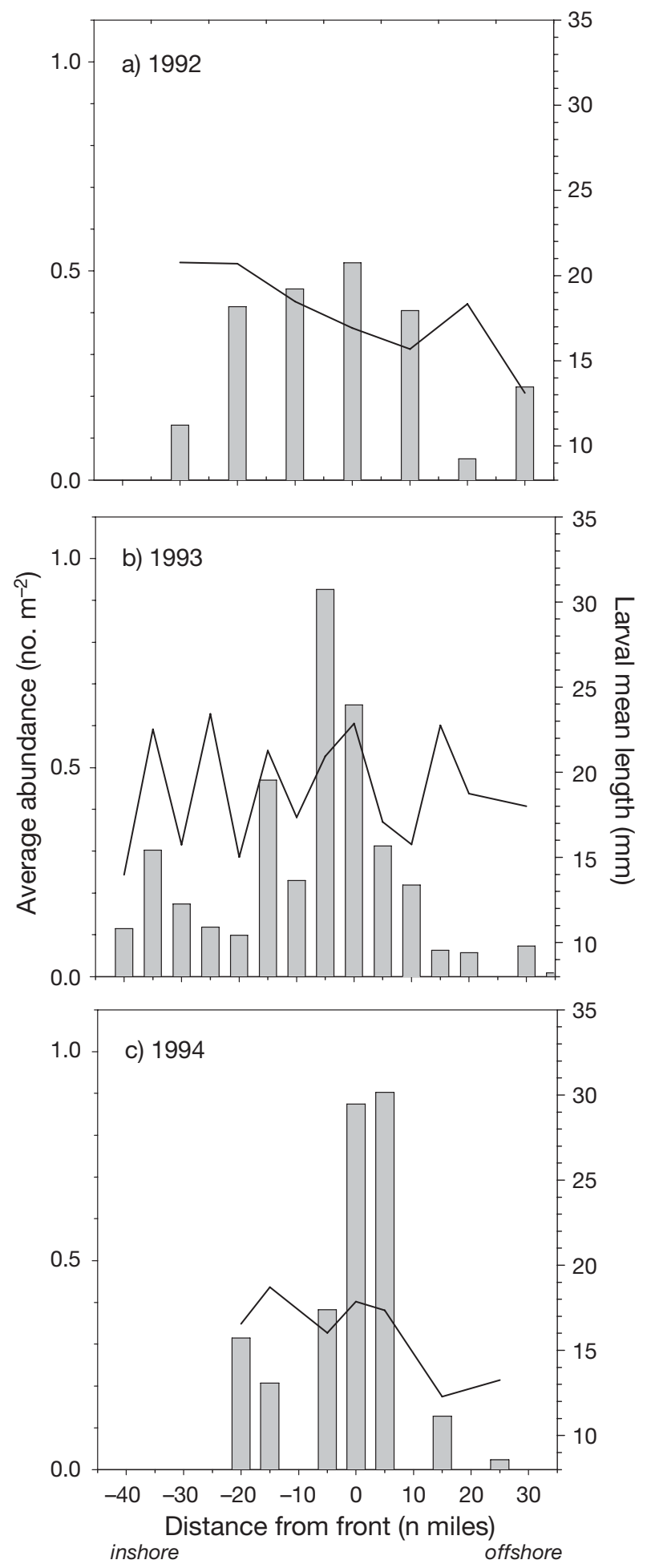

Fig. 4. Gadus morhua. Average abundance of larvae at different distances from front (bars); mean length of larvae (line) 


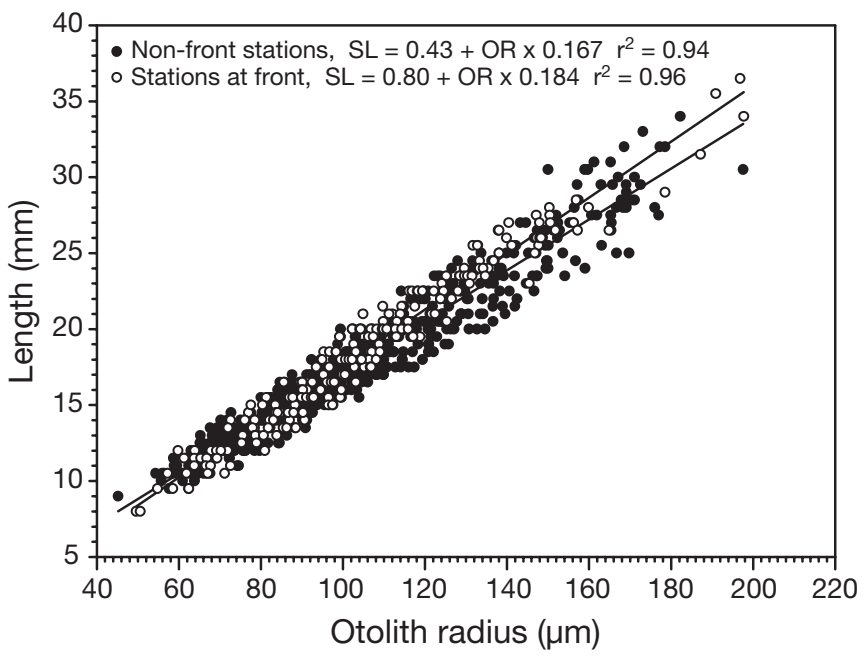

Fig. 5. Gadus morhua. Relationships between otolith radius (OR) and standard length (SL) of larvae. Different symbols and regressions describe the relationship for larvae on and outside front

\section{DISCUSSION}

The study demonstrates both enhanced growth rate of cod larvae and enhanced copepod abundance in the frontal zones of the North Sea. However, while peaks in larval growth rate were found exclusively at the

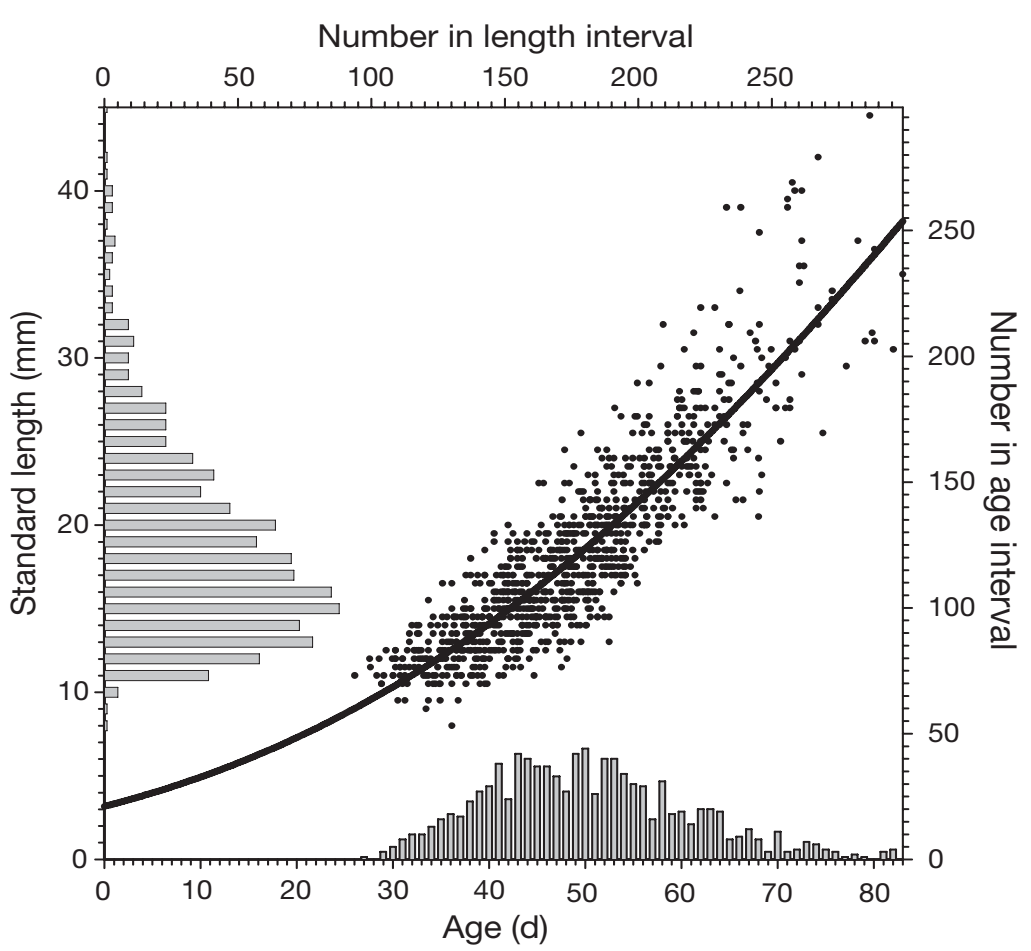

Fig. 6. Gadus morhua. Length and age distributions of larvae (bars). Datapoints: age-length relationship for each larva; curve: fit of all data to the Laird-Gompertz equation defined location of the front, estimated prey availability peaked in a wider zone around the front, with a tendency of highest values to the inshore side of the front. Hence, estimates of prey availability and larval growth rate at the stations were not significantly related. Growth rate estimates included growth during the preceding period, and the comparison to prey availability at time of sampling assumes that the observed distribution and abundance of copepods characterize the period covered by the growth analysis $(\sim 25 \mathrm{~d})$. This could not be verified from the present study, but studies conducted in March to April 2001 in the same area showed the same pattern of copepod distribution in relation to frontal features throughout the period (P. Munk unpubl. data). Likewise, the procedure used to estimate larval growth assumed that the groups of larvae sampled at different distances from the front had experienced the same physical conditions during the period analysed. The planktonic larvae drift with the currents and as both converging and diverging flow are seen in frontal zones, some cross-frontal advection might take place. During advection larval groups would, however, retain their relative position to the front and considering the relative large distances between stations $(18 \mathrm{~km})$, the relative short period considered for the growth analysis ( 25 d) and the potential rate of cross-frontal flow $\left(\sim 1 \mathrm{~m} \mathrm{~s}^{-1}\right.$, Aretxabaleta et al. 2005), it is not likely that larval groups had been advected from one station to another during the period of analysis. As an alternative to the present growth analysis based on length-at-age, estimation of recent growth can be carried out using the marginal increment widths of otoliths (Suthers et al. 1989, Zenitani 1999). However, a number of investigations indicate that under natural conditions it is difficult to distinguish changes in otolith width related to feeding conditions from changes caused by temperature fluctuations (e.g. Otterlei et al. 2002, Fey 2005). In addition the present findings of differences in the larva:otolith size relationships, which are possibly related to environmental conditions and growth pattern of larvae at frontal stations, will also affect such analysis.

Stomach analysis of cod larvae showed that only fractions of the total zooplankton present are available to the larvae, and that relative availability depends on species and size composition of the prey (Munk 1997, Gaard \& Reinert 2002). The present use of size- and species-specific prey preferences of larvae for evaluating 
Table 1. Laird-Gompertz regression estimates for stations sampled in 1992, 1993 and 1994 (see Fig. 1). SGRW: specific growth rate as weight

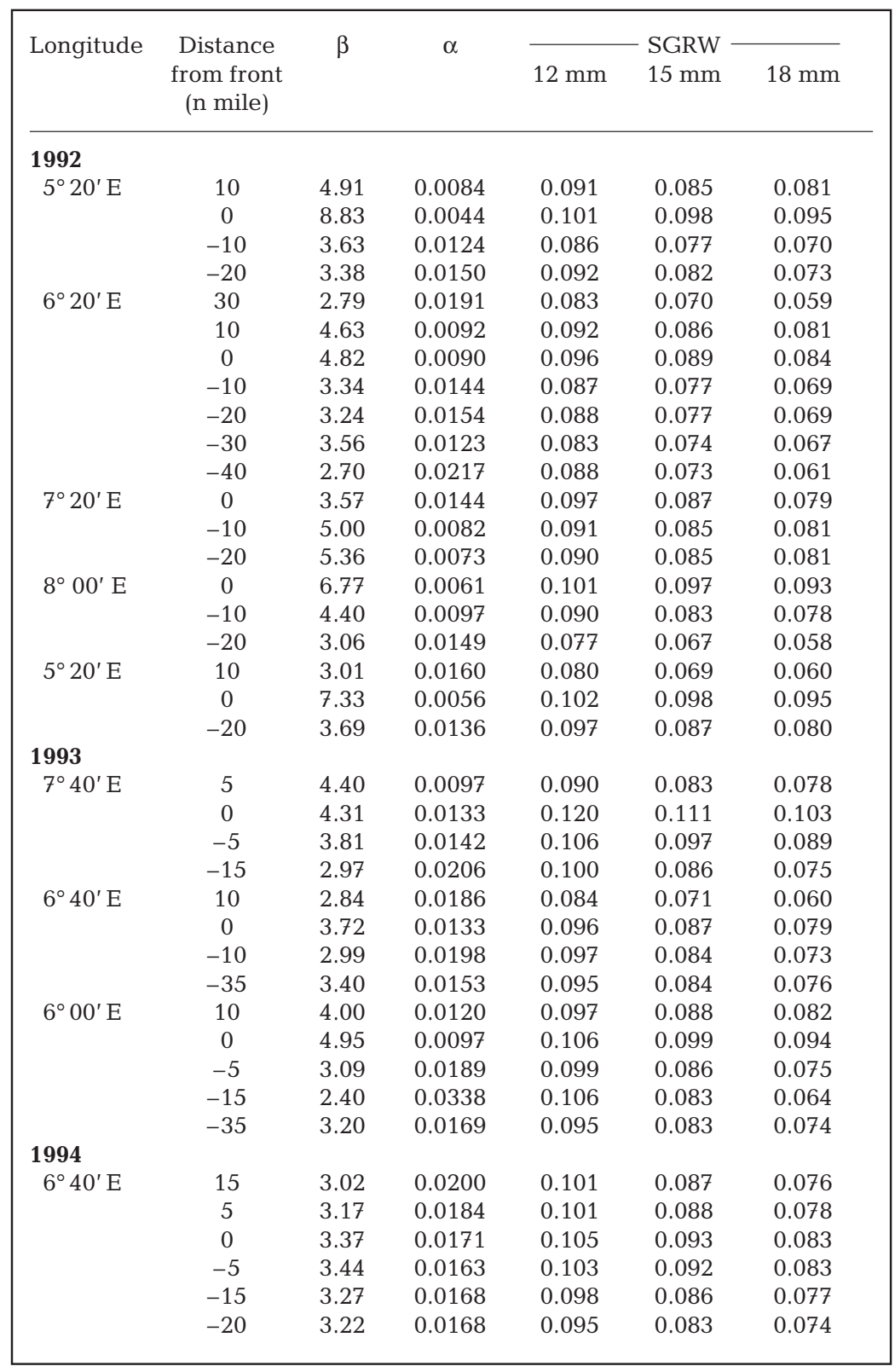

prey availability from total copepod abundance illustrates how important these considerations can be for evaluation of spatial variation in feeding conditions. Due to the large sizes of the abundant Calanus spp., many of these were unavailable to larvae in the size classes present, a circumstance that was marked in 1994 when only a minor part of the extraordinarily large population of Calanus spp. contributed to the diet of 12 to $18 \mathrm{~mm}$ larvae. However, when larvae grow to larger sizes the importance of Calanus spp. abundance increases markedly; for example in 1994 a 5-fold increase in prey was estimated for larvae during growth from 15 to $30 \mathrm{~mm}$ in size. For the Temora sp. and Acartia spp. in the inshore areas, a relatively low speciespreference of cod larvae for any copepod size markedly lowered estimates of their availability. As a consequence Pseudocalanus spp. (which was of appropriate size and highly preferred) came out as the species of primary importance to the populations of cod larvae, accounting for much of the cross-frontal variation in prey availability during the periods of investigation.

In the present study estimates of SGRW for $15 \mathrm{~mm}$ larvae ranged from 0.065 to $0.11 \mathrm{~d}^{-1}$. Other field-based estimates of growth rate for cod larva of approx. $15 \mathrm{~mm}$ are within the range of the present findings; e.g. a SGRW of $0.08 \mathrm{~d}^{-1}$ (at $5^{\circ} \mathrm{C}$ ) for larvae at Georges Bank (Bolz \& Lough 1988) and 0.04 to $0.085 \mathrm{~d}^{-1}$ (at 3 to $8^{\circ} \mathrm{C}$ ) for larvae at Browns Bank (Campana \& Hurley 1989), while SGRW estimates from mesocosm studies reach levels of 0.13 to $0.17 \mathrm{~d}^{-1}$ (6 to $12^{\circ} \mathrm{C}$ ) (Folkvord et al. 1994, Suthers et al. 1999). Beside variation in prey availability, temperature differences between study areas influence attainable growth rates (Folkvord 2005). Temperature up to $14^{\circ} \mathrm{C}$ has a significant positive effect on growth rate, and without food constrains mean SGRW of cod larvae $(\sim 12 \mathrm{~mm})$ range from 0.07 to $0.20 \mathrm{~d}^{-1}$ in the temperature range $4-14^{\circ} \mathrm{C}$ (Otterlei et al. 1999). Accordingly, observed attainable growth rate of 0.11 to $0.15 \mathrm{~d}^{-1}$, in the 6 to $8^{\circ} \mathrm{C}$ temperature range (Otterlei et al. 1999) is somewhat higher than the range of estimates in the present study, indicating that the cod larvae were to some degree food-limited. However, no effect of temperature on growth was evident in the present comparison based on temperature at catch.

Estimates of growth rates varied in both cross-frontal and along-frontal directions. Differences between the lowest and highest growth rate estimates at the front (Distance 0) were of the same magnitude as the observed 10 to $20 \%$ decline from the front to more distant sites. The along-frontal variability in growth rates could be related to differences in frontal performance across the investigated area, but also inappropriate spatial resolution of cross-frontal variability could lead to variability among peak estimates. Pronounced declines in growth rate es- 

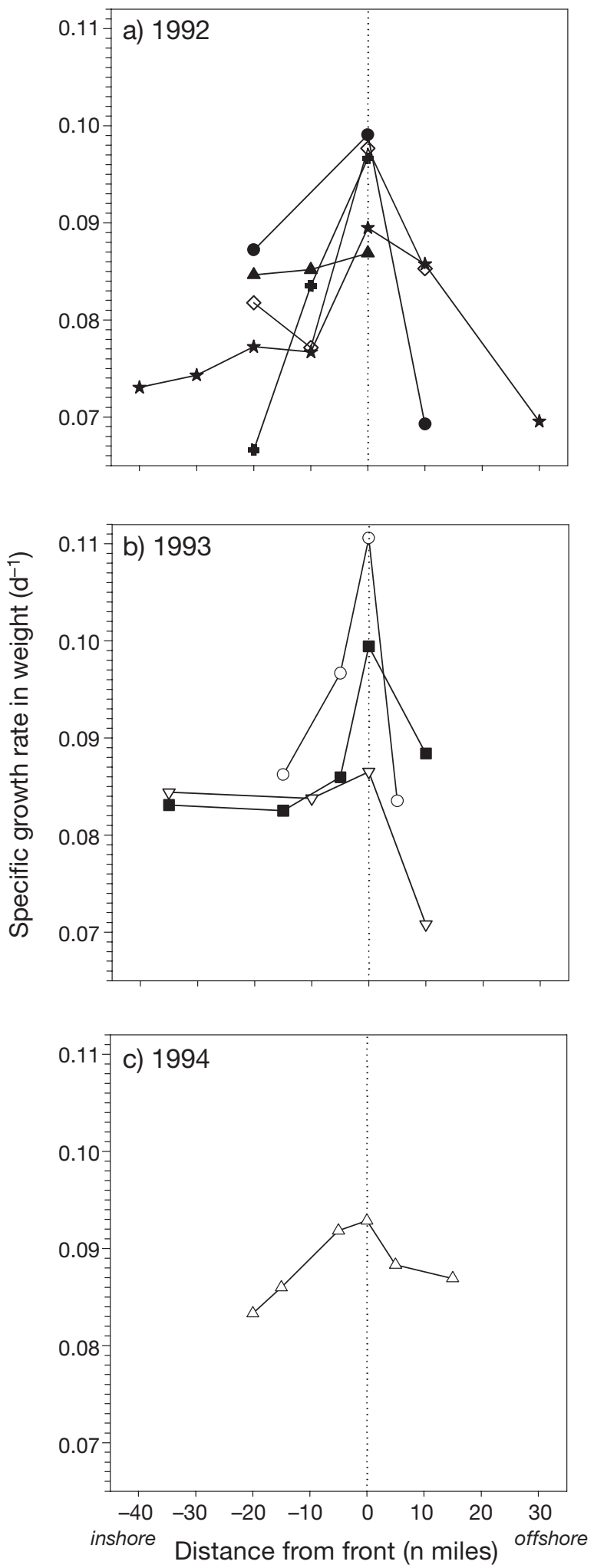

Fig. 7. Gadus morhua. Estimated specific growth rate in weight for $15 \mathrm{~mm}$ larvae sampled at different distances from front during the $3 \mathrm{yr}$ of sampling. Symbols and connecting lines indicate different transects timates (20 to $25 \%$ ) were observed between neighbouring stations, indicating that significant growth differences might occur at cross-frontal distances below the 5 to $10 \mathrm{n}$ miles used between stations in the present study.

Cross-frontal variation in growth has been shown for other larval fish species also. Immediately south of the present investigation area, Munk (1993) investigated the growth rate of larval sprat in relation to a coastal, tidal front along the west coast of Denmark. This study demonstrated a marked offshore decline in growth rate of larval sprat (up to $50 \%$ decline for $16 \mathrm{~mm}$ larvae), with less difference between growth rate estimates along the front (approx. 10\% difference between the lowest and highest estimates in the front). Lang et al. (1994) studied growth of yellowfin tuna larvae in frontal waters of the Mississippi River plume, and found a 10 to $20 \%$ reduction in larval growth rate from stations in the front to off-front stations, with the largest reduction on the offshore, oceanic side of the front.

The estimated variability in larval/juvenile growth potential is of a magnitude that could potentially influence larval survival and the subsequent recruitment. The size-at-age of larvae growing in different environments will diverge substantially through time. For example a difference in SGRW of about $0.013 \mathrm{~d}^{-1}$, which is the average difference between front and non-frontal stations for the range of analysed larval sizes in the present study, implies that a larva in the front could attain $40 \%$ higher weight during the first $30 \mathrm{~d}$ than a larva further offshore/inshore. The length difference in this example is approx. $1 \mathrm{~mm}$, and such a difference might not be ascertainable in the cross-frontal variation in larval mean lengths. However, such divergence in size could lead to differences in survivorship of larval groups. Campana (1996) estimated the survivorship of cod based on an annual variability in cod mean growth rates of $15 \%$, which is of the same order as the spatial variability in growth rates found in the present study. He used a constant instantaneous mortality rate of $0.1 \mathrm{~d}^{-1}$ (Campana et al. 1989), and for larvae having a $15 \%$ lower growth rate he estimated a 4 -fold increase in cumulative mortality to settlement (at $36 \mathrm{~mm}$ ) due to the longer larval period. The estimated effect would be even larger if the mortality rate was assumed to decline during ontogeny, for example by an inverse relationship between length and mortality rate (Pepin 1993). If we assume an inverse relationship and a mortality coefficient (as defined by Pepin, 1993) of 1.3, then a SGRW difference of $0.013 \mathrm{~d}^{-1}$ between front and nonfrontal larvae, as estimated in the present study, would lead to a 6-fold difference in larval survival from hatching to $36 \mathrm{~mm}$. Thus, if the fast-growing larvae in the front initially constituted, for example, $33 \%$ of the population, this group would later constitute $76 \%$ of all settling individuals. 
Differential growth and thereby differential mortality has implications for the interpretation of larval concentrations in frontal zones. The frequently observed aggregations of plankton organisms are mainly attributed to localised spawning behaviour of adults and accumulation due to an interplay of converging currents and vertically migrating behaviour of plankton organisms (Fortier et al. 1992, Franks 1992). However, no firm conclusion has been reached on the influence of differential mortality (e.g. Grimes \& Kingsford 1996, Lochmann et al. 1997). The positive effects of enhanced growth rates and shorter stage duration could be counterbalanced by other factors such as increased abundance of predators in the frontal zone (Grimes \& Kingsford 1996, Munk 2002). However, as shown above, the positive effect of increased growth rate could be of sufficient magnitude to override potential negative effects, and this must be taken into consideration in the interpretation of cross-frontal distribution patterns.

While a linkage between physical features and biological measures was apparent in the present study, it was not possible to link larval growth rate directly to prey availability. Methodological constraints may have been partly responsible, but findings might also indicate that prey availability, after reaching a certain level, becomes subordinate to other environmental influences. Temperature is of potentially great importance; however, there is little indication of a temperature increase in frontal areas. Other possibilities are water density and water turbulence, both of which are directly related to frontal processes and known to influence larval feeding and growth (Sclafani et al. 1993, MacKenzie 2000). Further studies of these physical-biological interactions are needed to enhance our understanding of how frontal processes influence larval ecology and survival.

Acknowledgements. I thank the crew of RV 'Dana' and other collaborators for great assistance during the surveys. Also thanks to colleagues and anonymous reviewers for helpful comments on the manuscript.

\section{LITERATURE CITED}

Aretxabaleta A, Manning J, Werner FE, Smith K, Blantona BO, Lynch DR (2005) Data assimilative hindcast on the southern flank of Georges Bank during May 1999: frontal circulation and implications. Cont Shelf Res 25:849-874

Bolz GR, Lough RG (1988) Growth through the first 6 months of Atlantic cod, Gadus morhua, and haddock, Melanogrammus aeglefinus, based on daily otolith increments. Fish Bull 86:223-235

Buckley LJ, Caldarone EM, Lough RG (2004) Optimum temperature and food-limited growth of larval Atlantic cod (Gadus morhua) and haddock (Melanogrammus aeglefinus) on Georges Bank. Fish Oceanogr 13:134-140
Campana SE (1996) Year-class strength and growth rate in young Atlantic cod Gadus morhua. Mar Ecol Prog Ser 135: $21-26$

Campana SE (2001) Accuracy, precision and quality control in age determination, including a review of the use and abuse of age validation methods. J Fish Biol 59:197-242

Campana SE, Hurley PCF (1989) An age- and temperaturemediated growth model for cod (Gadus morhua) and haddock (Melanogrammus aeglefinus) larvae in the Gulf of Maine. Can J Fish Aquat Sci 46:603-613

Campana SE, Frank KT, Hurley PCF, Koeller PA, Page FH, Smith PC (1989) Survival and abundance of Atlantic cod (Gadus morhua) and haddock (Melanogrammus aeglefinus) as indicators of year-class strength. Can J Fish Aquat Sci 46(Suppl 1):171-182

Cowan JH, Houde ED, Rose KA (1996) Size-dependent vulnerability of marine fish larvae to predation: an individualbased numerical experiment. ICES J Mar Sci 53:23-37

Fey DP (2005) Is the marginal otolith increment width a reliable recent growth index for larval and juvenile herring? J Fish Biol 66:1692-1703

Folkvord A (2005) Comparison of size-at-age of larval Atlantic cod (Gadus morhua) from different populations based on size- and temperature-dependent growth models. Can J Fish Aquat Sci 62:1037-1052

Folkvord A, Oeiestad V, Kvenseth PG (1994) Growth patterns of 3 cohorts of Atlantic cod larvae (Gadus morhua L.) studied in a macrocosm. ICES J Mar Sci 51:325-336

Fortier L, Levasseur ME, Drolet R, Therriault JC (1992) Export production and the distribution of fish larvae and their prey in a coastal jet frontal region. Mar Ecol Prog Ser 85: 203-218

Franks PJS (1992) Sink or swim: accumulation of biomass at fronts. Mar Ecol Prog Ser 82:1-12

Franks PJS, Chen C (1996) Plankton production in tidal fronts: a model of Georges Bank in summer. J Mar Res 54: 631-651

Gaard E, Reinert J (2002) Pelagic cod and haddock juveniles on the Faroe plateau: distribution, diets and feeding habitats, 1994-1996. Sarsia 87:193-206

Geffen AJ (1995) Growth and otolith microstructure of cod (Gadus morhua) larvae. J Plankton Res 17:783-800

Grimes CB, Kingsford MJ (1996) How do riverine plumes of different sizes influence fish larvae: Do they enhance recruitment? Mar Freshw Res 47:191-208

Houde ED (1987) Fish early life history dynamics and recruitment variability. Am Fish Soc Symp 2:17-29

Houde ED (1997) Patterns and trends in larval-stage growth and mortality. J Fish Biol 51(Suppl A):52-83

Lang KL, Grimes CB, Shaw RF (1994) Variations in the age and growth of yellowfin tuna larvae, Thunnus albacares, collected about the Mississippi river plume. Environ Biol Fish 39:259-270

Lee O, Nash DM, Danilowicz BS (2005) Small scale spatiotemporal variability in ichtyoplankton and zooplankton distribution in relation to a tidal-mixing front in the Irish Sea. ICES J Mar Sci 62:1021-1036

LeFevre J (1986) Aspects of the biology of frontal systems. Adv Mar Biol 23:164-281

Leggett EC, Deblois E (1994) Recruitment in marine fishes: is it regulated by starvation and predation in the egg and larval stages? Neth J Sea Res 32:119-134

Leising AW, Franks PJS (1999) Larval Atlantic cod (Gadus morhua) and haddock (Melanogrammus aeglefinus) growth on Georges Bank: a model with temperature, prey size, and turbulence forcing. Can J Fish Aquat Sci 56: $25-36$ 
Lochmann SE, Taggart CT, Griffin DA, Thompson KR, Maillet GL (1997) Abundance and condition of larval cod (Gadus morhua) at a convergent front on Western Bank, Scotian Shelf. Can J Fish Aquat Sci 54:1461-1479

MacKenzie BR (2000) Turbulence, larval fish ecology and fisheries recruitment: a review of field studies. Oceanol Acta 23(4):357-375

Meekan MG, Fortier L (1996) Selection for fast growth during the larval life of Atlantic cod Gadus morhua on the Scotian Shelf. Mar Ecol Prog Ser 137:25-37

Munk P (1993) Differential growth of larval sprat (Sprattus sprattus) across a tidal front in the eastern North Sea. Mar Ecol Prog Ser 99:17-29

Munk P (1997) Prey size spectra and prey availability of larval and small juvenile cod. J Fish Biol 51(Suppl A):340-351

Munk P (2002) Larval sand lance (Ammodytes sp.) in the diet of small juvenile wolfish (Anarhichas spp.): predatory interactions in frontal water masses off western Greenland. Can J Fish Aquat Sci 59:1759-1767

Munk P, Larsson PO, Danielsen DS, Moksness E (1995) Larval and small juvenile cod, Gadus morhua, concentrated in the highly productive areas of a shelf break front. Mar Ecol Prog Ser 125:21-30

Munk P, Larsson PO, Danielssen DS, Moksness E (1999) Variability in frontal zone formation and distribution of gadoid fish larvae at the shelf break in the northeastern North Sea. Mar Ecol Prog Ser 177:221-233

Nielsen R, Munk P (2004) Growth pattern and growth dependent mortality of larval and pelagic juvenile North Sea cod, Gadus morhua. Mar Ecol Prog Ser 278:261-270

Otterlei E, Nyhammer G, Folkvord A, Stefansson SO (1999) Temperature- and size-dependent growth of larval and early juvenile Atlantic cod (Gadus morhua): a comparative study of Norwegian coastal cod and northeast Arctic cod. Can J Fish Aquat Sci 56:2099-2111

Otterlei E, Folkvord A, Nyhammer G (2002) Temperature dependent otolith growth of larval and early juvenile

Editorial responsibility: Otto Kinne (Editor-in-Chief), Oldendorf/Luhe, Germany
Atlantic cod (Gadus morhua). ICES J Mar Sci 59: 401-410

Pepin P (1993) An appraisal of the size-dependent mortality hypothesis for larval fish - comparison of a multispecies study with a empirical review. Can J Fish Aquat Sci 50: 2166-2174

Pitchford JW, James A, Brindley J (2005) Quantifying the effects of individual and environmental variability in fish recruitment. Fish Oceanogr 14:156-160

Radtke RL (1989) Larval fish age, growth, and body shrinkage: information available from otoliths. Can J Fish Aquat Sci 46:1884-1894

Rice JA, Miller, TJ, Rose KA, Crowder LB, Marschall EA, Trebitz AS, Deangelis DL (1993) Growth-rate variation and larval survival-inferences from an individual-based size-dependent predation model. Can J Fish Aquat Sci 50:133-142

Sclafani M, Taggart CT, Thompson KR (1993) Condition, buoyancy and the distribution of larval fish: implications for vertical migration and retention. J Plankton Res 15: 413-435

Suthers IM, Frank KT, Campana SE (1989) Spatial comparison of recent growth in postlarval Atlantic cod (Gadus morhua) off southwestern Nova Scotia: inferior growth in a presumed nursery area. Can J Fish Aquat Sci 46: 113-124

Suthers IM, van der Meeren T, Jorstad KE (1999) Growth histories derived from otolith microstructure of 3 Norwegian cod stocks co-reared in mesocosms: effect of initial size and prey size changes. ICES J Mar Sci 56:658-672

Werner FE, Perry RI, Lough RG, Naimie CE (1996) Trophodynamics and advective influences on Georges Bank larval cod and haddock. Deep-Sea Res II 43:1793-1822

Zenitani H (1999) Size-specific changes in amount of lipid and daily growth rate of early larval sardine, Sardinops melanostictus, in the main Kuroshio Current and its offshore waters off eastern Japan. Mar Biol 134:645-652

Submitted: June 7, 2006; Accepted: September 1, 2006

Proofs received from author(s): March 8, 2007 